\title{
ANALYSIS OF SHORT-TERM SOLAR RADIATION DATA
}

\author{
Gayathri Vijayakumar \\ Sanford A. Klein \\ William A. Beckman \\ University of Wisconsin-Solar Energy Laboratory \\ 1500 Engineering Drive \\ Madison, WI, 53706 USA \\ beckman@engr.wisc.edu
}

\begin{abstract}
$\underline{\text { ABSTRACT }}$
Solar radiation data are available for many locations on an hourly basis. Simulation studies of solar energy systems have generally used these hourly values to estimate longterm annual performance, although solar radiation can exhibit wide variations during an hour. Variations in solar radiation during an hour, such as on a minute basis, could result in inaccurate performance estimates for some types of solar systems, such as photovoltaic systems, that respond quickly and non-linearly to solar radiation.
\end{abstract}

In addition, diffuse fraction correlations and cumulative frequency distribution curves have been developed using hourly data and the accuracy of these correlations when applied to short-term radiation has not been established. The purpose of this research is to investigate the inaccuracies caused by using hourly rather than short time (i.e., minute and three minute) radiation data on the estimated performance of solar energy systems. The inaccuracies are determined by examination of the frequency distribution and diffuse fraction relationships for short-term solar radiation data as compared to existing correlations and by comparing calculated radiation on tilted surfaces and utilizability based on hourly and shortterm radiation data.

\section{INTRODUCTION}

Analyses to predict long-term performances of solar energy systems rely on the availability of solar radiation data. These data generally include measurements of global horizontal radiation, diffuse radiation, and direct (beam normal) radiation. Hourly data are most commonly used in these analyses and are readily available; (e.g., hourly data for 239 US locations for 30 years are available through the National Solar Radiation Data Base). Variations in solar radiation data exist during an hour and measurements of 1-minute, 3-minute, and 5minute data have been made for a few locations and years.

The Integrated Surface Irradiance Study (ISIS) network is responsible for monitoring surface radiation in the United States and provides measurements of solar radiation data on a 1-minute basis for Madison, WI, and on a 3-minute basis for Albuquerque, NM, Bismarck, ND, Hanford, CA, Oak Ridge, TN, Madison, WI, Seattle, WA, Salt Lake City, UT, and Sterling, VA. One year of ISIS data, from November 2002 to October 2003 for each of these eight locations, were used in this research.

1-minute and 3-minute radiation data were analyzed to determine diffuse fraction as a function of clearness index and to determine frequency distributions. The influence of air mass on these relationships was also investigated. To assess the data in performance analyses of solar energy systems, the concept of solar radiation utilizability was used. Utilizability analyses are general, systemindependent, and can be easily used to compare the use of short-term solar radiation data to hourly data, without the need to do specific system simulations.

\section{DATA ANALYSIS}

Short-term variations in solar radiation data have not been extensively investigated. In many cases, diffuse radiation data are not available and they must be estimated knowing only the total radiation. Previous studies have shown that the diffuse fraction is correlated to the 
clearness index, defined as the ratio of the measured horizontal radiation to the extraterrestrial radiation on a horizontal surface for the same time period. Existing diffuse fraction correlations were developed based on hourly or daily radiation data and it is not known to what extent these correlations are applicable on shorter time scales. In addition, the variability of short-term radiation data and its effect on solar system performance have not been thoroughly investigated. One way to demonstrate the variability in solar radiation data is through frequency distributions as has been done by Suehrcke [1] and Gansler et al. [2]. The distributions, and the solar radiation utilizability that depends on them, are investigated in this study.

\subsection{Diffuse Fraction}

Because solar energy systems utilize beam and diffuse radiation differently, it is generally necessary to know the individual contributions in addition to their total. The estimation of radiation on a tilted surface also requires knowledge of the beam and diffuse components. If these components are not known, they can be estimated using diffuse fraction correlations.

Figure 1 is a plot of the measured diffuse fraction as a function of clearness index based on 3-minute data in Madison, WI for December 2002. This plot is typical of the diffuse fraction plots observed for other months and locations. The diffuse fraction should not, in theory, ever be greater than one. However, due to independent instrument measurements and low levels of radiation, this observation was made for cloudy mornings and evenings. For calculation purposes, the diffuse fraction was corrected to never exceed one.

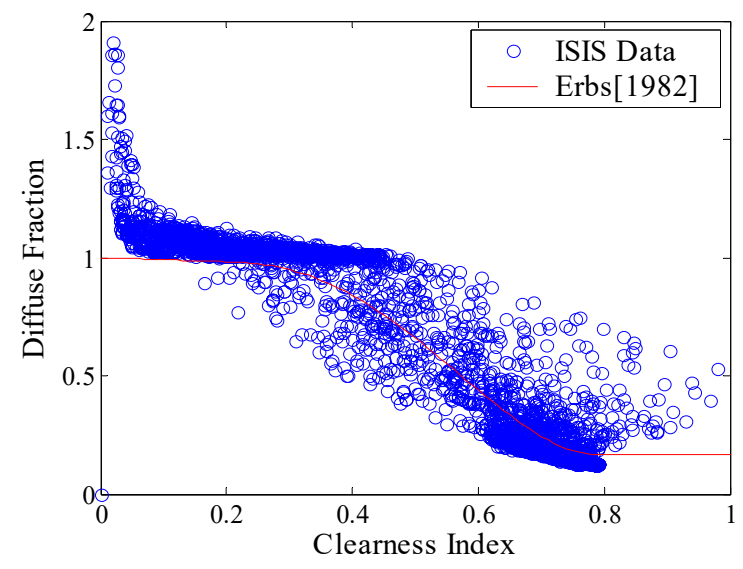

Fig. 1: Three minute diffuse fraction as a function of clearness index for December 2002, in Madison, WI.

Figure 2 shows the same relationship for a single clear day in April in Oak Ridge, representative of clear days in other locations. The diffuse fraction correlation developed by Erbs et al. [3], based on hourly radiation measurements, is shown on both plots for comparison. Figure 2 shows that for a clear day the diffuse radiation is overestimated when applying Erbs' correlation for hourly data to 3-minute data. This same result was observed for 1-minute data in Madison, WI.

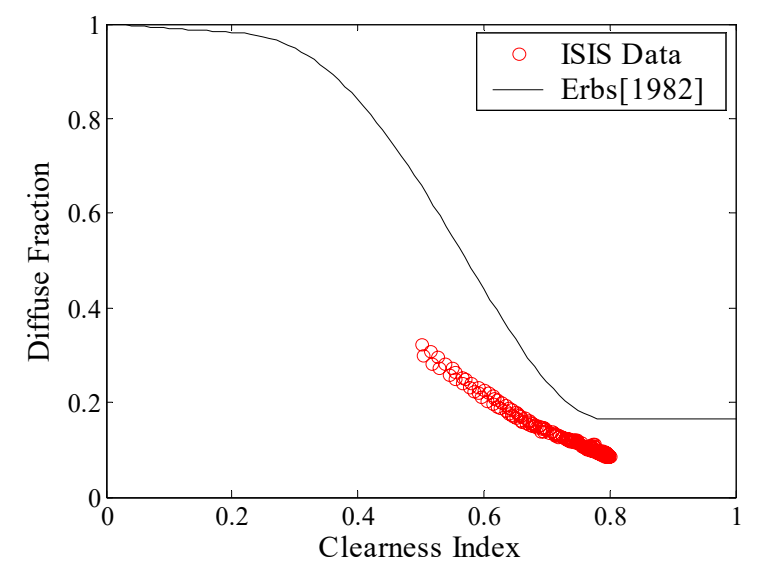

Fig. 2: Diffuse fraction as a function of clearness index for a clear April day in Oak Ridge, TN.

Gansler [4] suggested that the diffuse fraction depends on other factors such as relative humidity, ambient temperature, and air mass. Air mass, $m$, is defined as

$$
m=\frac{1}{\cos \theta_{z}}
$$

where $\theta_{z}$ is the solar zenith angle.

Figure 3 shows the air mass dependence of diffuse fraction for 3-minute radiation data for June 2002, in Hanford, CA.

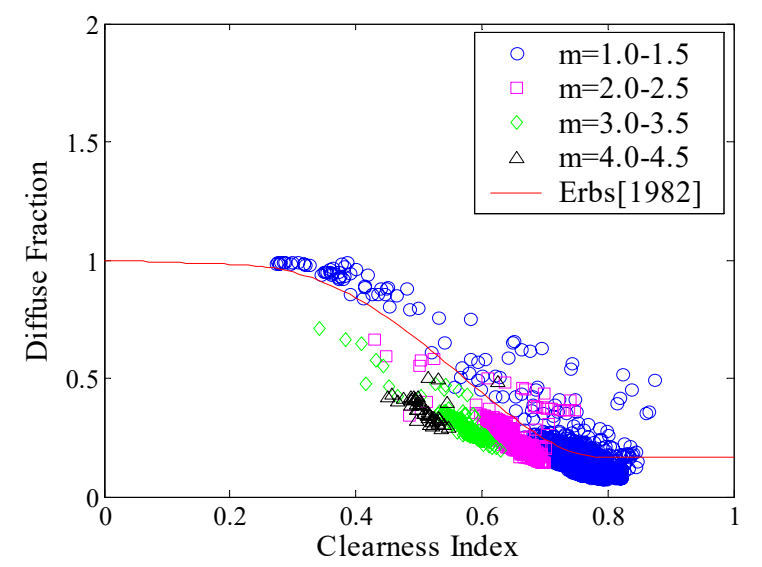

Fig. 3: The dependence of diffuse fraction on air mass for June 2002, Hanford, CA. 
The dependence on air mass is apparent on clear days, and less so on cloudy and partly cloudy days.

\subsection{Frequency Distribution of Solar Radiation}

The frequency distribution, i.e., the relative number of cloudy, average and sunny time periods that together form the average, is important in determining the performance of solar energy systems. The distribution can be represented in a non-dimensional manner in terms of the fractional time of occurrence of the daily clearness index, $K_{T}$, the ratio of the total radiation to the extraterrestrial radiation for a particular day. Liu and Jordan [5] showed that cumulative distributions representing the long-term average distribution of daily clearness index values are a unique function of $\bar{K}_{T}$, the monthly daily average clearness index. Generalized distribution curves were developed by Liu and Jordan and equations representing these curves were developed by Bendt et al. [6] based on 20 years of data from 90 locations and are shown in Fig. 4.

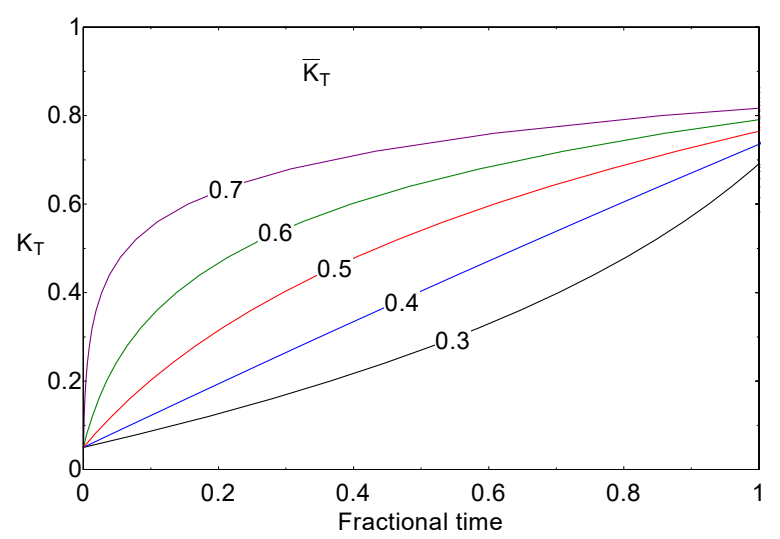

Fig. 4: Generalized daily distribution of $K_{T}$ as a function of $\bar{K}_{T}$ from Bendt et al. [6].

The results from Suehrcke's analysis of 1-minute data in Perth, Australia, showed a strong bimodal distribution that differed greatly from the Bendt distributions.

Gansler's results from a similar analysis of 1-minute data in San Antonio, Albany, and Atlanta, also showed significant differences from the Bendt et al. distributions, but not the strong bimodal shape as observed by Suehrcke.

Figure 5 shows the cumulative frequency distribution of 3-minute clearness indices for Sterling, VA, for a one year time period. Clearness indices were grouped according to their hourly clearness index for comparison to the Bendt et al. correlation.



Fig. 5: Frequency distribution of 3-minute clearness indices in Sterling, VA, grouped by hourly average.

The bimodal behavior was not observed in the 8 locations used in this study, however the distributions did vary significantly from Bendt et al. Although the correlations were developed for daily clearness indices, they had been shown by Whillier [7] to be applicable to hourly clearness indices. Figure 5 shows that these distributions do not represent clearness indices based on 3-minute data as well.

The air mass dependence of the short-term distribution of solar radiation was investigated. Figure 6 shows the frequency distribution of 3-minute clearness indices for Albuquerque, grouped by hourly clearness index and by air mass.

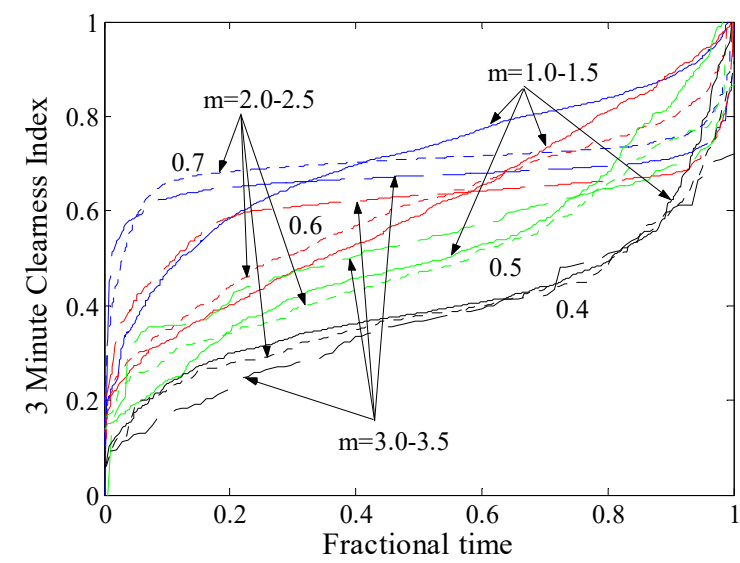

Fig. 6: Frequency distribution of 3-minute clearness indices in Albuquerque, NM, grouped by hourly average and air mass, $m$.

The strong air mass dependence, particularly at high air mass values, was observed in all 8 locations and supports 
Gansler's conclusion that frequency distribution correlations for short-term radiation data should be developed as functions of air mass and hourly clearness index. The development of such correlations would allow locations, where short-term data is unavailable, to use available hourly averages to predict the distribution of short-term clearness indices. If a diffuse fraction correlation were also developed for short-term data, the diffuse and beam components of the total radiation could also be estimated. If it were not computationally prohibitive, these short-term data could then be used in calculations and performance analyses. Attempts at such correlations have been made by Gansler[4], Skartveit and Olseth[8], and Tovar, Olmo, and Alados-Arboledas[9].

\section{RADIATION ON A TILTED SURFACE}

Calculation of the hourly radiation on a tilted surface, $I_{T}$, allows for a quantitative estimate of the impact of using short-term data rather than hourly data. Radiation data on a tilted surface were calculated using Equation 2, the Liu and Jordan [10] method in four methods.

$$
I_{T}=I_{b} \cdot R_{b}+I_{d} \cdot\left(\frac{1+\cos \beta}{2}\right)+I \cdot \rho_{g} \cdot\left(\frac{1-\cos \beta}{2}\right)
$$

where $\rho_{g}$ is the ground reflectance and $R_{b}$ is the ratio of the beam radiation on a tilted surface to that on a horizontal surface defined as

$$
R_{b}=\frac{\cos \theta}{\cos \theta_{z}}
$$

The first two methods apply Equation 2 to available shortterm(i.e., 1 or 3-minute) radiation data to calculate shortterm radiation on a tilted surface. These tilted radiation values were then summed to create hourly tilted radiation values. The difference between the first two methods is the method of calculation of the beam radiation that is a variable in Equation 2. In the first method, beam radiation on the horizontal surface is determined from the available beam normal radiation measurements using geometric relationships. In the second method, beam radiation on the horizontal surface is calculated as the difference between the measurements of total and diffuse radiation. The third method sums the short-term total radiation for an hour and applies the Erbs hourly correlation to the summed hourly values to determine the hourly beam and diffuse components. These values are then used in Equation 2 to determine the hourly radiation on the tilted surface. The final method applies Erbs hourly correlation directly to the short-term radiation data to calculate short-term diffuse and beam components. Liu and Jordan's model is then used to calculate short-term radiation on a tilted surface. These short-term values are then summed to create hourly tilted radiation values.

The differences in the results of the four methods are small, although there is a trend that on clear days the available short-term data results in higher values than the Erbs data, and on cloudy days this trend is reversed. Also, the Erbs diffuse correlation appears to work equally well when applied to short-term data as when applied to hourly data. Results from the other locations show similar behavior.

To quantify this observance, the daily average tilted radiation for a given month was calculated for each month, for each location. Table 1 shows the results using 1-minute data from Madison, WI, and Figure 7 shows the results using 3-minute data from Madison, WI. Some months were not used in the study due to missing data.

TABLE 1: MONTHLY AVERAGE DAILY TILTED RADIATION $\bar{H}_{T}$

\begin{tabular}{|lcccc|}
\hline Month & \multicolumn{4}{c|}{ Madison } \\
\cline { 2 - 5 } & Method & Method & Method & Method \\
& 1 & 2 & 3 & 4 \\
\hline Jan & 11.6 & 11.6 & 11.8 & 11.9 \\
Feb & 15.8 & 16.1 & 16.5 & 16.6 \\
Mar & 15.3 & 15.6 & 16.1 & 16.3 \\
Apr & 17.0 & 17.3 & 17.5 & 17.6 \\
Jun & 18.4 & 20.3 & 20.6 & 20.6 \\
Jul & 19.4 & 20.1 & 20.4 & 20.4 \\
Aug & 20.3 & 20.9 & 21.0 & 21.2 \\
Sep & 17.7 & 18.3 & 18.1 & 18.4 \\
Nov & 10.1 & 10.2 & 10.4 & 10.7 \\
Dec & 10.2 & 10.2 & 10.2 & 10.2 \\
\hline
\end{tabular}

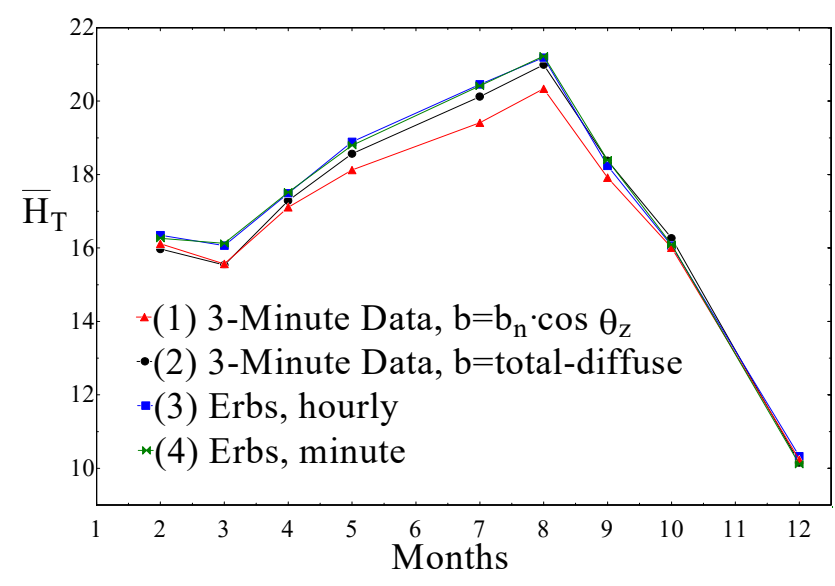

Fig. 7: Comparing 4 methods of calculating monthly average daily tilted radiation from 3-minute data in Madison, WI. Note expanded scale. 


\section{UTILIZABILITY}

The utilizability concept can be used to evaluate the performance of many types of solar energy systems, including active, passive and photovoltaic systems [11]. Utilizability is defined as the fraction of the solar radiation incident on a surface that exceeds a specified threshold or critical level, $I_{C}$. The monthly average daily utilizability, $\bar{\phi}$, can be calculated if the critical level is assumed constant over all time periods of the day. It is then the fraction of a month's solar radiation incident on a surface between sunrise and sunset that exceeds the critical level.

$$
\bar{\phi}=\frac{\sum_{\text {days hours }} \sum_{\text {days }}\left(I-I_{C}\right)^{+}}{\sum_{\text {hours }} I}
$$

Utilizability was determined for a range of critical levels by applying critical levels to short-term and hourly beam normal radiation values. Short-term beam normal utilizability was calculated from both measurements of beam normal and from the difference between total and diffuse radiation. In this latter case, both diffuse radiation measurements and the Erbs correlation were used to determine the diffuse fraction. Utilizability analyses for these short-term beam normal data were compared to the ISIS 3-minute beam normal data, as shown in Figures 8 and 9.

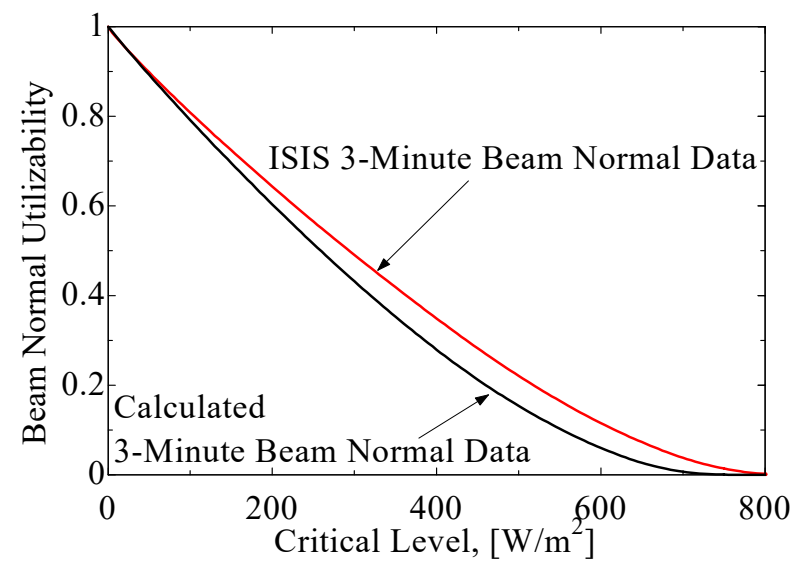

Fig. 8: Comparison of average daily beam normal utilizability for January in Seattle for calculated and actual short-term data.

Figure 8 shows the discrepancy between using actual measurements of beam normal and using values calculated from other available data. This difference results from the measurements being taken with independent instruments. The magnitude of this difference varies by location, and months where the calculated data results in greater utilizability were also observed.

Currently, performance analyses in locations where limited data are available use hourly diffuse fraction correlations to determine diffuse and beam radiation from the available total. Figure 9 and 10 show how such analyses can greatly underestimate the true performance of a system.

Applying the Erbs diffuse correlation to 3-minute data for this month and location significantly underestimates utilizability, as seen in Figure 9 for January in Seattle.

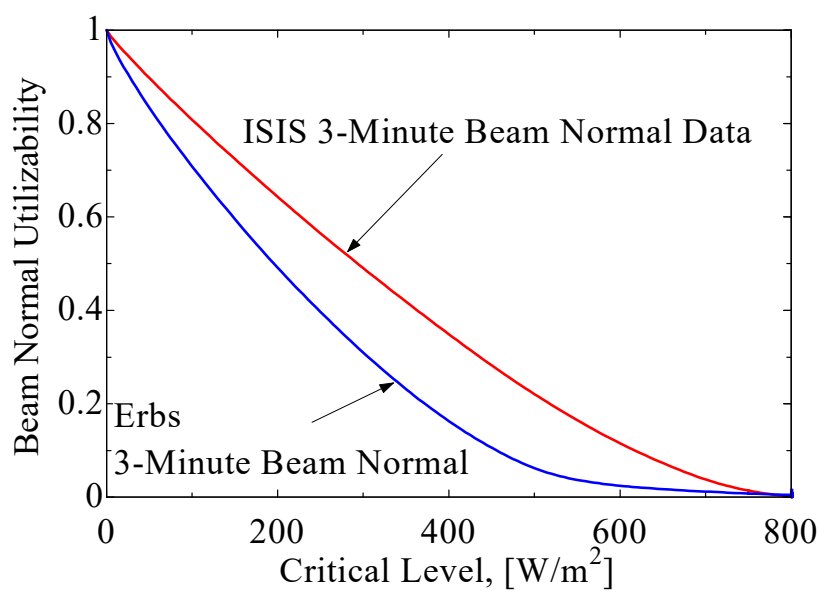

Fig. 9: Comparison of average daily beam normal utilizability for January in Seattle for actual and correlated short-term data.



Fig. 10: Comparison of average daily beam normal utilizability for January in Seattle for actual short-term data and hourly correlated data. 
In Figure 10 the Erbs correlation is applied to hourly data, as is more commonly done. This option also resulted in an underestimate of utilizability. There were months and locations where the opposite behavior was also observed, and Erbs resulted in greater utilizability. This occurs because the Erbs correlation can both underestimate and overestimate the amount of beam radiation, depending on the type of day, as seen in Figure 1. The distribution of days therefore greatly influences the results of the utilizability analyses.

The argument for using short-term radiation data rather than hourly data is apparent in Figure 11. Variations in beam normal radiation during an hour can lead to greater utilizability than would be indicated in an analysis using hourly data. This result was found consistently among all months and all locations, although the magnitude of the underestimation varied.

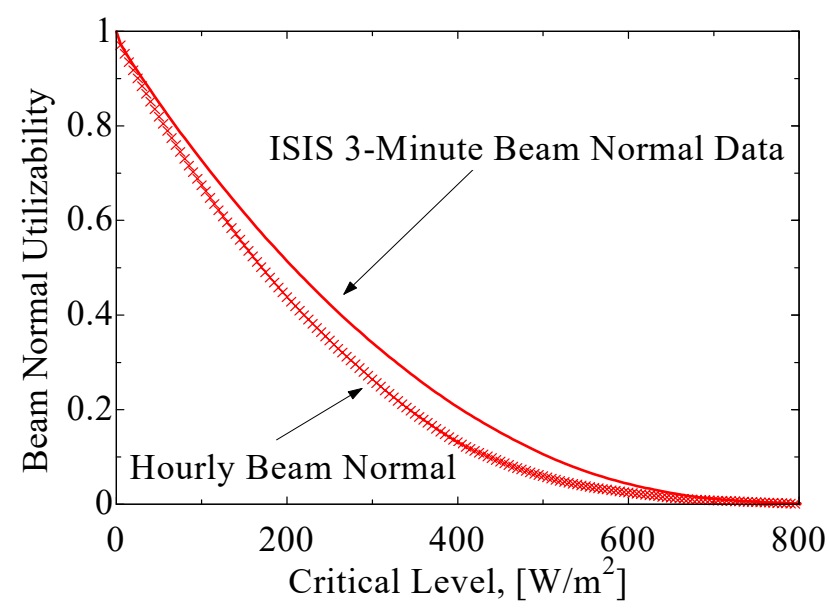

Fig. 11: Comparison of average daily beam normal utilizability for January in Hanford for short-term data and hourly data.

\section{CONCLUSIONS}

The analyses presented here confirm that the variations in solar radiation within an hour cannot be considered negligible when conducting performance analyses of solar energy systems. The distribution of short-term radiation within an hour results in greater utilizability, if the shortterm data varies significantly. On a clear day when the variation within the hour is minimal, the magnitude of the error decreases. On a partly cloudy day when large variations exist within the hour, hourly analyses will underestimate the true performance of a system.

The development of diffuse fraction correlations and frequency distributions of short-term data as functions of air mass will allow users the ability to accurately generate short-term data from commonly available hourly averages. These short-term data can then be used in simulations and performance analyses of solar energy systems, if it is not computationally prohibitive to do so.

\section{REFERENCES}

(1) Suehrcke, H. and McCormick, P.G., "The diffuse fraction of instantaneous insolation values," Solar Energy, Vol. 40, 1988, p.423-430

(2) Gansler, R., Klein, S.A., and Beckman, W.A., "Investigation of minute solar radiation data," Solar Energy, Vol. 55, 1995, p.21-27

(3) Erbs, D.G., Klein, S.A., and Duffie, J.A., "Estimation of the Diffuse Radiation Fraction for Hourly, Daily, and Monthly-Average Global Radiation," Solar Energy, Vol. 28, 1982, p.13

(4) Gansler, R., Assessment of generated meteorological data for use in solar energy simulations. M.S.Thesis, Mechanical Engineering Deparment, Univ. of WisconsinMadison, Madison(1993)

(5) Liu, B.Y.H., and Jordan, R.C., "The Interrelationship and Characteristic Distribution of Direct, Diffuse and Total Solar Radiation," Solar Energy, Vol. 4, 1960, p.1 (6) Bendt, P., Collares-Pereira, M., and Rabl, A., "The Frequency Distribution of Daily Radiation Values," Solar Energy, Vol. 27, 1981, p.1

(7) Whillier, A., "The Determination of Hourly Values of Total Radiation from Daily Summations," Arch. Met. Geoph. Biokl. Series B, Vol.7, 1956, p.197

(8) Skartveit, A. and Olseth, J.A., "The Probability Density and Autocorrelation of Short-Term Global and Beam Irradiance," Solar Energy, Vol. 49, 1992, p.477487

(9) Tovar, J., Olmo, F.J., and Alados-Arboledas, L., "One-Minute Global Irradiance Probability Density Distributions Conditioned to the Optical Air mass," Solar Energy, Vol. 62, 1998, p.387-393

(10) Liu, B.Y.H. and Jordan, R.C., "Daily Insolation on Surfaces Tilted Toward the Equator," ASHRAE Journal, Vol. 3, 1962, p.53

(11) Klein, S.A., and Beckman, W.A., "Review of Solar Radiation Utilizability," Journal of Solar Energy

Engineering, Vol.106, 1984, p.393 